Infection in Vietnam", Am J Public Health. 99(2), pp. 439-444.

7. Kimberly Green và các cộng sự (2010), "Integrating Palliative Care Into HIV Outpatient Clinical Settings: Preliminary Findings From an Intervention Study in Vietnam", Journal of Pain and Symptom Management. 40(1), pp. 31-34.

8. Maria Giulia Nanni và các cộng sự (2015), "Depression in HIV infected patients: a review",
Current psychiatry reports. 17(1), pp. 530.

9. Jacob K Saravanan B, Jonhson $S$, et al (2007), "Belief models in first episode schizophrenia in South India", Social psychiatry and psychiatric epidemiology. 42(6), pp. 446-451.

10. Cohen N. L Srinivasan J, Parikh S. V. (2003), "Patient attitudes regarding causes of depression: implications for psychoeducation", Canadian Journal of Psychiatry. 48(7), pp. 493-495.

\title{
ĐÁNH GIÁ CHẤT LƯợNG CUộC SỐNG BẰNG THANG ĐIỂM HEARTQOL CHO BÊ̂NH NHÂN CAN THIỆP ĐộNG MACH QUA DA
}

\section{TÓM TẮT}

Mục tiêu: Xác định đặc điểm và một số yếu tố liên quan đến chất lượng sống của người bệnh sau can thiệp động mạch vành (ĐMV) qua da bằng thang điểm HeartQ̉oL taii Bệnh Viện Tim Hà Nội. Đối tượng và phương pháp: mô tả tiến cứu theo dõi dọc 150 người bệnh can thiệp ĐMV qua da tại Bệnh Viện Tim Hà Nội từ $1 / 6 / 2020$ đến 28/2/2021, sử dụng thang điểm HeartQoL để đánh giá chất lượng cuộc sống (CLCS) tại các thời điểm nghiên cứu. Kết quả: Tuổi trung bình là $63.7 \pm 10$ tuổi. Tỉ lệ giới nam (66.7\%). Điểm trung bình CLCS theo thang điểm HeartQoL tại các thời điểm sau can thiêp (từ $2.1 \pm 0.4$ đến $2.5 \pm$ 0.3) cao hơn, có sự khác biệt so với trước can thiệp $(1.9 \pm 0.5) p<0.001$. Điểm CLCS thuộc lĩnh vực thể chất $(1.9 \pm 0.4$ đến $2.4 \pm 0.4) p<0.05$, điểm thuộc lĩnh vức cảm xúc $(2.7 \pm 0.4$ đến $2.8 \pm 0.3)$ cao hởn lĩnh vực thể chất và cải thiện theo thời gian $p<0.05$. Còn đ̛̉au ngực sau can thiệp ảnh hưởng đến chất lượng cuộc của người bệnh. Tình trạng suy tim khó thở theo NYHA có điểm CLCS thấp hơn bệnh nhân không có triệu chứng, nữ giới thấp hơn nam giới. Tuổi $<60$ tuổi, bệnh nhân có trình độ học vấn cao có điểm CLCS cao hởn $(p<0,05)$. Kết luận: CLCS của người bênh tốt nhất sau sáu tháng can thiệp ĐMV qua da. Các yễu tố ảnh hưởng đến CLCS bao gồm: giới tính, trình độ học vân, nhóm tuổi, còn tình trạng đau ngực và suy tim sau can thiêp.

Tư khóa: Chất lượng cuộc sống, HeartQoL, can thiệp động mạch vành qua da

\section{SUMMARY \\ ASSESSMENT OF THE QUALITY OF LIFE IN PATIENTS AFTER PERCUTANEOUS CORONARY INTERVENTION BY THE HEARTQOL SCALE \\ Objectives: The goal of the study was investigated the quality of life for patients after Percutaneous Coronary Intervention (PCI) by HeartQol questionnaire.}

*Bệnh viện Tim Hà Nội

Chịu trách nhiệm chính: Phan Thị May

Email: maypt.vthn@gmail.com

Ngày nhận bài: 28.6.2021

Ngày phản biện khoa học: 23.8.2021

Ngày duyệt bài: 30.8.2021

\section{Phan Thị May*, Phạm Như Hùng* và cs.}

Methods \& Results: From June 2020 to February 2021, we prospectively enrolled 150 patients after percutaneous coronary intervention, aged $63.7 \pm 10.3$ years $(66,7 \%$ male) were measured by HeartQoL score. The average score of overall quality of life after PCI is singnificantly improved before intervention $(2.1 \pm 0.4$ to $2.5 \pm 0.3 ; p<0.001)$. Quality of life score in the physical domain aspects singnificantly improves from $1.9 \pm 0.4$ before PCI to $2.4 \pm 0.4$ after PCI $(p<0.05)$. The sex characteristics, education level, age, chest pain after PCI and NYHA are related to the quality of life of patients after PCI $(p<0.05)$. Conclusion : Our study shows that the majority of patients had improved quality of life after six months of PCI. Sex characteristics, education level, age, chest pain after PCI and NYHA are related to the quality of life of patients.

Keywords: HeartQol, Percutaneous Coronary Intervention, Cardiovascular

\section{I. ĐĂT VẤN ĐỀ}

Cùng với sự phát triển kinh tế xã hội, vấn đề CLCS được quan tâm nhiều hơn. Hiện nay, xu thế chăm sóc và điêu trị chung trền thế giới không chỉ giải quyết vấn đề về bệnh lý mạch vành mà cần quan tâm giải quyết tổng thể các yếu tố tác động, ảnh hưởng lên chất lượng sống của người bệnh. Hiện nay có khá nhiểu thang điểm, bộ công cụ đánh giá CLCS như bộ câu hỏi SF-36, Macnew, Seattle Angina, thang điểm HeartQoL. Bộ câu hỏi HeartQoL đánh giá mức độ ảnh hưởng của bệnh lý mạch vành sau can thiệp lên các lĩnh vực hoạt động thể chất, lĩnh vực cảm xúc của người bệnh. Đánh giá CLCS của người bệnh sau can thiệp ĐMV qua da là cân thiết, quan trọng, qua đó giúp nhân viên y tế có cách nhìn tồng quát hơn, giúp người bệnh có CLCS tốt hơn cả về thể chất lấn tinh thân. Tại Việt Nam, việc sử dụng thang điểm HeartQoL để đánh giá CLCS của người bệnh sau can thiệp ĐMV qua da chưa được áp dụng. Vì vậy, chúng tôi tiến hành nghiên cứu đề tài này với hai mục tiêu là xác định đặc điểm CLCS ở người bệnh sau can thiệp 
ĐMV qua da bằng thang điểm HeartQoL và tìm hiểu một số yếu tố liên quan đến CLCS của những người bệnh này.

\section{II. ĐốI TƯợNG VÀ PHƯƠNG PHÁP NGHIÊN CỨU \\ 2.1. Đối tượng nghiên cứu}

Tiêu chuẩn lựa chọn: bệnh nhân được can thiệp ĐMV qua da tại Bệnh Viện Tim Hà Nội từ tháng 6/2020 đến hết tháng 2/2021.

Tiêu chuẩn loại trứ: bệnh nhân không đồng ý tham gia nghiên cứu, bệnh nhân bị các tình trạng nặng phải điều trị Hồi sức, tử vong và không được theo dõi đầy đủ.

2.2. Phương pháp nghiên cứu và cách tiến hành. Nghiên cứu mô tả tiến cứu có so sánh trước sau can thiệp, cõ̃ mẫu thuận tiện.

Công cụ nghiên cứu: Bộ câu hỏi theo thang điểm HeartQoL.

Các bước tiến hành: Phỏng vấn và lập phiếu đông thuận tham gia nghiên cứu trước can thiệp. Thời gian phỏng vấn sau can thiệp (1 tháng, 3 tháng và 6 tháng).

Các chỉ tiêu nghiên cứu và đánh giá: 10 câu đánh giá CLCS thuộc lĩnh vực thể chất, 4 câu đánh giá CLCS thuộc lĩnh vực cảm xúc. Điểm đánh giá câu hỏi theo các mức từ 0 đến 3 . Mức 0 (ảnh hưởng rất nhiều), mức 1 (ảnh hưởng nhiêu), 2 (ảnh hưởng rất ít), 3 (không ảnh hưởng). Điểm càng cao tương ứng với mức độ ảnh hưởng ít tương ứng với chất lượng sống càng tốt.

Xử lý thống kê bằng chương trình SPSS phiên bản 22.0.

\section{KẾT QUẢ NGHIÊN CỨU}

3.1. Đặc điểm chung của đối tượng nghiên cứu

Bảng 1. Đặc điểm chung của đôî tượng nghiên cứu

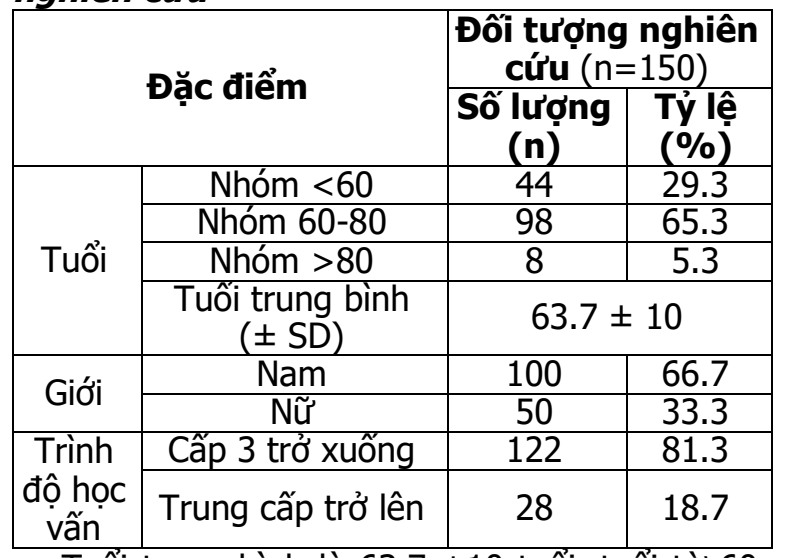

Tuối trung bình là $63.7 \pm 10$ tuối, tuối từ 6080 tuổi có tỉ lệ cao nhất chiếm $66 \%$. Trình độ học vấn cấp 3 trở xuống có tỉ lệ $81,3 \%$. Nam (66.7\%) nhiều hơn nữ (33.3\%).

3.2. Điểm chất lượng cuộc sống của người bệnh can thiệp mạch vành

Bảng 2. Sự thay đổi điểm chất lượng cuộc sống theo thang điểm HeartQoL của người bệnh trước và sau can thiệp tại thời điểm nghiên cứu

\begin{tabular}{|c|c|c|c|c|c|}
\hline Diểm CLCS & \multicolumn{2}{|c|}{ Thời điếmTrước Can thiêp ${ }^{(1)}$} & $\begin{array}{c}\text { Sau } 1 \text { tháng } \\
(\mathrm{n}=150)\end{array}$ & $\begin{array}{c}\text { Sau } 3 \text { tháng }{ }^{(3)} \\
(\mathrm{n}=150)\end{array}$ & $\begin{array}{l}\text { Sau } 6 \text { tháng }{ }^{(4)} \\
(n=150)\end{array}$ \\
\hline \multirow{6}{*}{$\begin{array}{c}\text { HeartQoL } \\
(X \pm S D) \\
\max , \min \end{array}$} & \multirow{2}{*}{$\begin{array}{l}\text { Theo thế } \\
\text { chất }\end{array}$} & \multirow{2}{*}{$\begin{array}{c}1.6 \pm 0.6 \\
(0.3-3.0)\end{array}$} & $1.9 \pm 0.4(0.6-2.7)$ & $2.2 \pm 0.5(0.6-3)$ & $2.4 \pm 0.4(1.3-3)$ \\
\hline & & & $<0.001$ & $p_{(1-3)<0.001}$ & $<0.001$ \\
\hline & \multirow{2}{*}{$\begin{array}{c}\text { Theo cảm } \\
\text { xúc }\end{array}$} & \multirow{2}{*}{$\begin{array}{c}2.4 \pm 0.3 \\
(1.5-3.0)\end{array}$} & $2.7 \pm 0.4(1-3)$ & $2.7 \pm 0.4(1-3)$ & $0.3(1-3)$ \\
\hline & & & $p_{(1-2)}<0.001$ & $P_{(1-3)}<0.001$ & $<0.001$ \\
\hline & \multirow{2}{*}{ Tổng điểm } & \multirow{2}{*}{$\begin{array}{c}1.9 \pm 0.5 \\
(0.6-3.0)\end{array}$} & $2.17 \pm 0.4(1.0-2.8)$ & $2.3 \pm 0.4(1-3)$ & $2.5 \pm 0.3(1.2-3)$ \\
\hline & & & $\mathrm{P}_{(1-2)}<0.001$ & $P_{(1-3)}<0$. & $P_{(1-4)}<0.001$ \\
\hline
\end{tabular}

p*: Paired Samples T Test

Điểm trung bình CLCS theo HeartQoL tại các thời điểm nghiên cứu sau can thiệp $(2.1 \pm 0.4$ đến $2.5 \pm 0.3)$ cao hơn và có sự khác biệt so với trước can thiệp $(p<0.001)$. Điểm CLCS thuộc lính vực thể chất sau can thiệp cải thiện tăng dần theo thời gian $(1.9 \pm 0.4$ đến $2.4 \pm 0.4)$, điểm cảm xúc ( $2.7 \pm 0.4$ đến $2.8 \pm 0.3$ ) tăng cao ngay sau 1 tháng sau đó ổn định ở tháng thứ 3 và tháng thứ 6 $(p<0,001)$. Điểm CLCS thuộc lînh vực thể chất thấp hơn điểm CLCS thuộc lĩnh vực cảm xúc.

3.3. Các yếu tố liên quan đến chất lượng sống của người bệnh sau can thiệp động mạch vành qua da

Bảng 3. Môi liên quan giữa điểm HeartQoL với tuổi, giới tính và học vấn

\begin{tabular}{|c|c|c|c|c|c|}
\hline \multicolumn{2}{|c|}{ Thời điểm } & \multicolumn{4}{|c|}{ Điểm HeartQoL $(n=150)$} \\
\hline \multicolumn{2}{|l|}{ Yếu tố } & $\begin{array}{l}\text { Trước } \\
\text { Can thiệp } \\
(\mathrm{n}=150)\end{array}$ & $\begin{array}{c}\text { Sau can } \\
\text { thiệp } 1 \text { tháng } \\
(\mathrm{n}=150)\end{array}$ & $\begin{array}{c}\text { Sau can } \\
\text { thiệp } 3 \text { tháng } \\
(\mathrm{n}=150)\end{array}$ & $\begin{array}{c}\text { Sau can } \\
\text { thiệp } 6 \text { tháng } \\
(\mathrm{n}=150)\end{array}$ \\
\hline \multirow{2}{*}{$\begin{array}{l}\text { Đô } \\
\text { tuổi }\end{array}$} & $<60^{(1)}(\mathrm{n}=44)$ & $2.0 \pm 0.4(1.2-2.6)$ & $2.3 \pm 0.4(1.1-2.8)$ & $2.5 \pm 0.4(1.5-3)$ & $2.7 \pm 0.4(1.2-3)$ \\
\hline & $60-80^{(2)}(n=98)$ & $1.9 \pm 0.5(0.6-3.0)$ & $2.1 \pm 0.3(1-2.8)$ & $2.3 \pm 0.4(1-3)$ & $2.5 \pm 0.3(1.4-3)$ \\
\hline
\end{tabular}


VIETNAM MEDICAL JOURNAL N02 - SEPTEMBER - 2021

\begin{tabular}{|c|c|c|c|c|c|}
\hline & $>80^{(3)}(n=8)$ & $1.4 \pm 0.4(0.7-2.0)$ & $2.0 \pm 0.3(1.2-2.4)$ & $2.1 \pm 0.5(1-2.7)$ & $2.4 \pm 0.2(2-2.7)$ \\
\hline & p* & $p_{(1-2-3)}=0.01$ & $\mathrm{P}_{(1-2-3)}=0.03$ & $p_{(1-2-3)}=0.02$ & $p_{(1-2-3)}=0.03$ \\
\hline & p** & $\mathrm{p}_{(1-2)}=0.07$ & $\mathrm{p}_{(1-2)}=0.004$ & $p_{(1-2)}=0.006$ & $p_{(1-2)}=0.001$ \\
\hline \multirow{4}{*}{ Giơoi } & $\operatorname{Nam}^{(\mathbf{1})}(\mathrm{n}=100)$ & $1.9 \pm 0.5(0.6-3.0)$ & $2.2 \pm 0.3(1.0-2.8)$ & $2.4 \pm 0.5(1.0-3.0)$ & $2.6 \pm 0.3(1.4-3.0)$ \\
\hline & $N \tilde{u}^{(2)}(n=50)$ & $1.8 \pm 0.4(0.6-2.6)$ & $2.0 \pm 0.3(1.1-2.6)$ & $2.3 \pm 0.4(1.3-3.0)$ & $2.4 \pm 0.4(1.3-2.9)$ \\
\hline & $p^{*}$ & $p_{(1-2)}=0.6$ & $\mathrm{P}_{(1-2)}<0.001$ & $\mathrm{P}_{(1-2)}=0.2$ & $\mathrm{P}_{(1-2)}<0.001$ \\
\hline & p** & $\mathrm{p}_{(1-2)}=0.4$ & $\mathrm{P}_{(1-2)}<0.001$ & $\mathrm{p}_{(1-2)}=0.08$ & $p_{(1-2)}=0.001$ \\
\hline \multirow{4}{*}{$\begin{array}{l}\text { Trình độ } \\
\text { học vấn }\end{array}$} & Cấp 3 trở xuống & $1.8 \pm 0.5(0.6-2.7)$ & $2.1 \pm 0.4(1.0-2.8)$ & $2.3 \pm 0.4(1.0-3.0)$ & $2.5 \pm 0.3(1.3-3.0)$ \\
\hline & Trung cấp trở lên (2) & $2.0 \pm 0.4(1.4-3.0)$ & $2.3 \pm 0.3(1.6-2.8)$ & $2.5 \pm 0.4(1.4-3.0)$ & $2.7 \pm 0.2(2.2-3.0)$ \\
\hline & p* & $p_{(1-2)}=0.04$ & $P_{(1-2)}=0.008$ & $p_{(1-2)}=0.03$ & $p_{(1-2)}=0.02$ \\
\hline & $p^{* *}$ & $\mathrm{p}_{(1-2)}=0.08$ & $p_{(1-2)}=0.007$ & $p_{(1-2)}=0.03$ & $p_{(1-2)}=0.02$ \\
\hline
\end{tabular}

$\mathrm{p}^{*}$ : One Way - ANOVA, independent sample T-Test, ; $\mathrm{p}^{* *}$ : Correlate.

Điểm HeartQoL có sự khác biệt giữa các nhóm tuổi $(p<0.05)$, bệnh nhân dưới 60 tuổi có điểm HeartQoL cao nhất (từ $2.0 \pm 0.4$ lên 2.7 \pm 0.4 ).

Điểm HeartQoL theo giới tính có sự khác biệt ở thời điểm sau can thiệp 1 tháng và 6 tháng ( $p$ $<0.001$ ). Điểm CLCS của nữ (từ $1.8 \pm 0.4$ đến $2.4 \pm 0.4$ ) thấp hơn nam (từ $1.9 \pm 0.5$ đến $2.6 \pm$ 0.3). Giới tính có liên quan đến điểm HeartQoL

của người bệnh sau can thiệp 1 tháng và 6 tháng $(p<0.05)$. Tại thời điểm 3 tháng, đặc điểm giới tính không liên quan đến điểm HeartQoL của người bệnh ( $p>0.05)$.

Trình độ học vấn từ cấp ba trở xuống có điểm HeartQoL $(1.8 \pm 0.4$ đến $2.5 \pm 0.3)$ thấp hơn so với người bệnh có trình độ học vấn cao hơn (2.0 \pm 0.3 đến $2.7 \pm 0.2) p<0.05$.

Bảng 4. Môi liên quan giữa điểm HeartQoL với tình trạng đau ngực, suy tim theo NYHA và tinh trạng sức khỏe

\begin{tabular}{|c|c|c|c|c|c|}
\hline \multirow{2}{*}{\multicolumn{2}{|c|}{ Yếu tố }} & \multicolumn{4}{|c|}{ Điếm HeartQoL $(\mathrm{n}=150)$} \\
\hline & & $\begin{array}{c}\text { Trước } \\
\text { Can thiệp }\end{array}$ & $\begin{array}{c}\text { Sau can } \\
\text { thiệp } 1 \text { tháng }\end{array}$ & $\begin{array}{c}\text { Sau can } \\
\text { thiệp } 3 \text { tháng }\end{array}$ & $\begin{array}{c}\text { Sau can } \\
\text { thiệp } 6 \text { tháng }\end{array}$ \\
\hline \multirow{4}{*}{$\begin{array}{l}\text { Đau } \\
\text { ngực }\end{array}$} & Không đau ${ }^{(1)}$ & $2.2 \pm 0.5(1.2-3.0)$ & $2.2 \pm 0.3(1.0-2.8)$ & $2.5 \pm 0.4(1.0-3.0)$ & $2.6 \pm 0.3(1.5-3.0)$ \\
\hline & Có đau ${ }^{(2}$ & $1.8 \pm 0.5(0.6-2.6)$ & $2.0 \pm 0.3(1.1-2.8)$ & $2.0 \pm 0.5(1.0-3.0)$ & $2.3 \pm 0.4(1.2-3.0)$ \\
\hline & $p^{*}$ & $p_{(1-2)}=0.01$ & $\mathrm{P}_{(1-2)}<0.001$ & $\mathrm{P}_{(1-2)}<0.001$ & $\mathrm{p}_{(1-2)}<0.001$ \\
\hline & $\mathrm{p}^{* *}$ & $<0.001$ & $<0.001$ & $<0.001$ & $<0.001$ \\
\hline \multirow{6}{*}{$\begin{array}{l}\text { Theo } \\
\text { NYHA }\end{array}$} & Không suy tim ${ }^{(1)}$ & $2.2 \pm 0.3(1.4-3)$ & $2.2 \pm 0.3(1.0-2.8)$ & $2.4 \pm 0.4(1.2-3.0)$ & $2.6 \pm 0.3(1.4-3.0)$ \\
\hline & $\mathrm{I}^{(2)}$ & $1.8 \pm 0.1(1.6-2.1)$ & $2.0 \pm 0.3(1.5-2.5)$ & $2.2 \pm 0.5(1.0-2.8)$ & $2.3 \pm 0.4(1.7-2.8)$ \\
\hline & II $^{(3)}$ & $1.5 \pm 0.1(1.3-2.1)$ & $1.9 \pm 0.3(1.1-2.5)$ & $2.0 \pm 0.4(1.1-2.9)$ & $2.2 \pm 0.4(1.2-2.8)$ \\
\hline & III $^{(4)}$ & $0.9 \pm 0.2(0.6-1.4)$ & $1.9 \pm 0.1(1.7-2.0)$ & $1.7 \pm 0.6(1.0-2.2)$ & $1.9 \pm 0.2(1.6-2.2)$ \\
\hline & p* & $\mathrm{P}_{(1-2-3-4)}<0.001$ & $\mathrm{P}_{(1-2-3-4)}=0.004$ & $\mathrm{P}_{(1-2-3-4)<0.001}$ & $\mathrm{P}_{(1-2-3-4)}<0.001$ \\
\hline & $\mathrm{p}^{* *}$ & $<0.001$ & $<0.001$ & $<0.001$ & $<0.001$ \\
\hline \multirow{5}{*}{$\begin{array}{c}\text { Theo } \\
\text { cảm } \\
\text { nhận } \\
\text { sức } \\
\text { khỏe }\end{array}$} & Tệ ${ }^{(1)}$ & $1.7 \pm 0.1(1.5-1.8)$ & $1.2 \pm 0.3(0.6-1.7)$ & $1.6 \pm 0.3(1.2-2.5)$ & $2.6 \pm 0$ \\
\hline & Bình thường ${ }^{(2)}$ & $1.8 \pm 0.5(0.6-2.7)$ & $1.9 \pm 0.4(0.8-2.7)$ & $2.3 \pm 0.4(1.0-3.0)$ & $2.5 \pm 0.3(1.2-3.0)$ \\
\hline & Tốt ${ }^{(3)}$ & $2.1 \pm 0.3(1.4-2.7)$ & $2.3 \pm 0.3(1.7-2.7)$ & $2.7 \pm 0.2(2.0-3.0)$ & $2.7 \pm 0.2(2.3-3.0)$ \\
\hline & $p^{*}$ & $p_{(1-2-3)}=0.07$ & $\mathrm{P}_{(1-2-3)}<0.001$ & $\mathrm{P}_{(1-2-3)<0.001}$ & $\mathrm{P}_{(1-2-3)<0.001}$ \\
\hline & $\mathrm{p}^{* *}$ & 0.03 & $<0.001$ & $<0.001$ & 0.007 \\
\hline
\end{tabular}

$\mathrm{p}^{*}$ : One Way - ANOVA, independent sample T-Test ; $\mathrm{p}^{* *}$ : Correlate

Điểm HeartQoL có sự khác biệt giữa có triệu chứng đau ngực và không đau ngực tại các thời điểm trước và sau can thiệp $(p<0.05)$, không đau ngực có điểm CLCS (2.2 \pm 0.3 đến $2.6 \pm 0.3$ ) cao hơn nhóm đau ngực ( $2.0 \pm 0.3$ đến $2.3 \pm 0.4$ ).

Tình trang suy tim theo NYHA có sự khác biệt $(p<0.05)$ tại các thời điểm trước và sau can thiệp,

không có triệu chứng suy tim sau can thiệp có điểm CLCS ( $2.2 \pm 0.3$ đến $2.6 \pm 0.3)$, NYHA độ III có điểm CLCS thấp $(1.7 \pm 0.6$ đến $1.9 \pm 0.1)$.

Điểm CLCS về tình trạng sức khỏe giữa các nhóm trước can thiệp không có sự khác biệt ( $p>0.05)$, có sự khác biệt giữa các nhóm sau can thiệp $(\mathrm{p}<0.001)$.

Bảng 5. Đặc điểm lâm sàng liên quan đến chât lượng cuộc sống

\begin{tabular}{|c|c|c|c|c|c|}
\hline D & Thời điếm & $\begin{array}{c}\text { Trước can } \\
\text { thiêep } \\
\text { (1) }^{(1)}(\mathrm{n}=150)\end{array}$ & $\begin{array}{c}\text { Sau } 1 \text { tháng(2) } \\
(\mathrm{n}=150)\end{array}$ & $\begin{array}{c}\text { Sau } 3 \text { tháng } \\
(\mathrm{n}=150)\end{array}$ & $\begin{array}{l}\text { Sau } 6 \text { tháng }{ }^{(4)} \\
(n=150)\end{array}$ \\
\hline & Không & $91(60.7)$ & 109(72.7) & $114(76)$ & $117(78)$ \\
\hline & Độ I & $12(8)$ & $14(9.3)$ & $10(6.7)$ & $10(6.7)$ \\
\hline
\end{tabular}




\begin{tabular}{|c|c|c|c|c|c|}
\hline & Đô̂ II & $30(20)$ & $23(15.3)$ & $23(15.3)$ & $20(13.3)$ \\
\hline & Độ III - IV & $17(11.4)$ & $4(2.7)$ & $3(2.0)$ & $3(2.0)$ \\
\hline & $p$ & -- & $\mathrm{P}_{(1-2)}<0.001$ & $\mathrm{P}_{(1-3)}<0.001$ & $\mathrm{P}_{(1-4)}<0.001$ \\
\hline \multirow{3}{*}{$\begin{array}{c}\text { Đau ngực } \\
(\mathrm{n}, \%)\end{array}$} & Có & $29(10.7)$ & $52(34.7)$ & $47(31.3)$ & $34(22.7)$ \\
\hline & không & $121(89.3)$ & $98(65.3)$ & $103(68.7)$ & $116(77.3)$ \\
\hline & $\mathrm{p}$ & -- & $\mathrm{P}_{(1-2)}<0.001$ & $P_{(1-3)} 0.003$ & $\mathrm{p}_{(1-4)} 0.38$ \\
\hline \multirow{4}{*}{$\begin{array}{c}\text { Theo cảm } \\
\text { nhận sức } \\
\text { khỏe } \\
(\mathrm{n}, \%)\end{array}$} & Tệ & $8(5.3)$ & $14(9.3)$ & $10(6.7)$ & $1(0.7)$ \\
\hline & Bình thường & $128(85.3)$ & $115(76.7)$ & $115(76.7)$ & $127(84.7)$ \\
\hline & Tốt & $14(9.4)$ & $21(14)$ & $25(16.6)$ & $22(21)$ \\
\hline & $\mathrm{p}^{*}$ & -- & $\mathrm{p}_{(1-2)}=0.8$ & $\mathrm{p}_{(1-3)}=0.15$ & $P_{(1-4)}=0.01$ \\
\hline
\end{tabular}

$\mathrm{p}^{*}$ : Paired Samples T Test.

Tình trạng suy tim phân đô theo NYHA sau can thiệp có sự khác biệt so với thời điểm trước can thiệp $(p<0.001)$. Tình trạng đau ngực sau can thiệp 1 tháng, 3 tháng có sự khác biệt so với trước can thiệp $(p<0.05)$. Tình trạng sức khỏe sau can thiệp 6 tháng có sự khác biệt so với trước can thiệp $(p<0.05)$.

\section{BÀN LUẦN}

4.1. Đặc điểm chung. Kết quả (bảng 1) cho thây độ tuổi trung bình của đối tượng nghiên cứu của chúng tôi là $63.7 \pm 10$ tuổi. kết quả này tương tự một số nghiên cứu trên thang điểm khác, Nguyễn Thị Kim Sáng - Trung tâm MEDIC nghiên cứu "Chất lượng cuộc sống sau can thiệp ĐMV trên bênh nhân hội chứng vành cấp hoắc bệnh tim thiếu máu cục bộ dựa trên bộ câu hỏi Seattle Angina" năm 2019, độ tuổi trung bình là $65 \pm 11.6[1]$. Như vâyy phân bố tuổi trong nghiên cứu của chúng tôi là phù hợp. Bệnh nhân có trình độ học vấn cấp 3 trở xuống chiếm tỉ lệ cao $81,3 \%$, trình độ trung cấp trở lên chiếm $18.7 \%$. Giới nam $(66.7 \%)$ nhiều hơn gấp 2 lần so với nữ giới $(p<0.001)$.

4.2. Chất lượng cuộc sống của người bệnh sau can thiệp mạch vành qua da. Kết quả (bảng 2), điểm HeartQoL tại thời điểm sau can thiệp (2.1 \pm 0.4 đến $2.5 \pm 0.3)$ cao hơn so với trước can thiệp (1.9 \pm 0.5$)$. Điểm CLCS lĩnh vực thể chất sau can thiệp $(1.9 \pm 0.4$ đến $2.4 \pm$ 0.4 ) có sự khác biệt giữa các thời điểm $(p<0.001)$. Điểm CLCS lĩnh vực cảm xúc (2.7 \pm 0.4 đến $2.8 \pm 0.3$ ), có sự khác biệt tại các thời điểm sau can thiệp $(p<0.001)$. Như vậy, CLCS của người bệnh hồi phục dần và tốt nhất tại thời điểm 6 tháng sau can thiệp. Các yếu tố liên quan đến bệnh và can thiệp ảnh hưởng nặng nề nhất từ lúc nhập viên đến sau 1 tháng, thời điểm 3 tháng trở đi các yếu tố này giảm dần. Kết quả này của chúng tôi phù hợp với các nghiên cứu khác, Darvispour cho thây CLCS của người bệnh trước và sau can thiệp 3 tháng có sự khác biệt $(p<0.001)$ [2].

\subsection{Các yếu tố liên quan đến chất lượng}

cuộc sống của người bệnh sau can thiệp động mạch vành qua da. Kết quả (bảng 3 ) cho thấy điểm HeartQoL giữa các nhóm tuối trước và sau can thiệp có sự khác biệt $(p<0.05)$, bệnh nhân dưới 60 tuổi có điểm HeartQoL cao nhất (từ $2.0 \pm 0.4$ lên $2.7 \pm 0.4$ ). Nhóm bệnh $>80$ tuổi có điểm HeartQoL thấp nhất. Như vâyy, nhóm tuổi có liên quan chặt chẽ tới điểm HeartQoL của người bệnh tại các thời điểm sau can thiệp $p<0.05$. Kết quả này cũng phù hợp với các nghiên cứu khác, Ruijie Li cho thấy CLCS của người bệnh sau can thiệp ĐMV qua da giảm theo tuổi với giá trị $\mathrm{p}<0.001$ [5]. Can thiệp ĐMV qua da giúp người bệnh cao tuổi cải thiện đáng kể về bênh tuy nhiên sự phục hồi về hoạt động thể chất thường chậm hơn so với những bệnh nhân trẻ tuổi có can thiệp ĐMV qua da [6].

Kết quả (bảng 3), điểm HeartQoL theo giới tính có sự khác biệt ở thời điểm sau can thiệp 1 tháng và 6 tháng $(p<0.001)$. Điểm HeartQoL của nữ (từ $1.8 \pm 0.4$ đến $2.4 \pm 0.4$ ) thấp hơn nam (1.9 \pm 0.5 đến $2.6 \pm 0.3)$, sau can thiệp 1 tháng và 6 tháng có sự khác biệt $(p<0.05)$. Tại thời điểm 3 tháng, đặc điểm giới tính không liên quan đến điểm CLCS của người bệnh $(p>0.05)$. Nhu vậy, giới tính có liên quan đển CLCS của người bệnh. Nữ giới có điểm HeartQoL thấp hơn nam giới đăc biệt ở lĩnh vực thể chất. Bệnh nhân nữ trẻ mắc bệnh ĐMV cấp tính có điểm CLCS thuộc lĩnh vực thể chất và tinh thần kém hơn so với nam giới [3]. Các nghiên cứu khác cũng cho thấy CLCS của nữ giới thấp hơn so với nam giới ở các lĩnh vực thể chất, cảm xúc và mối quan hệ xã hội trong vòng 6 tháng đầu sau can thiệp [4]. Điều này thường do phụ nữ ít được hỗ trợ xã hội, phải đảm nhận nhiều vai trò hơn ở nơi làm việc và ở nhà so với nam giới.

Kết quả (bảng 3), trình độ học vấn từ cấp ba trở xuống có điểm HeartQoL $(1.8 \pm 0.4$ đến 2.5 \pm 0.3 ) thấp hơn so với người bệnh có trình độ học vấn cao hơn $(2.0 \pm 0.3$ đến $2.7 \pm 0.2) p<$ 0.05. Đặc điểm trình độ học vấn của đối tượng nghiên cứu có liên quan, ảnh hưởng đến điểm 
CLCS của người bệnh sau can thiệp ĐMV qua da, người có trình độ học vấn cao hơn có điểm CLCS cao hơn. Mối quan hệ này đã chỉ ra trong nhiều nghiên cứu [7]. Như vậy, giáo dục thay đổi thái đô và kiến thức của con người đối với sức khỏe và có thể dẫn đến cải thiên CLCS.

Kết quả (bảng 4 và 5) cho thây điểm CLCS có sự khác biệt giữa có triệu chứng đau ngực và không đau ngực tại các thời điểm trước và sau can thiệp $(p<0.05)$. Nhóm không đau ngực tại mỗi thời điểm nghiên cứu có điểm HeartQoL ( 2.2 \pm 0.3 đến $2.6 \pm 0.3$ ) cao hơn nhóm đau ngực $(2.0 \pm 0.3$ đến $2.3 \pm 0.4)$. Tình trang đau ngực sau can thiệp 1 tháng, 3 tháng có sự khác biệt so với trước can thiệp với giá trị $p<0.05$. Không có sự khác biệt so với thời điểm sau can thiệp 6 tháng. Như vậy, triẹu chứng đau ngực sau can thiệp có ảnh hưởng đến CLCS của người bệnh. Một số nghiên cứu cho thấy nữ giới có tình trạng đau ngực tái phát nhiều hơn so với nam giới. Triêu chứng đau thắt ngực kéo dài sẽ ảnh hưởng rất lớn đến CLCS của người bệnh đặc biệt trong lĩnh vực thể chất [8]. Một nghiên cứu khác cũng cho thấy chi phí điều trị cho bênh nhân đau thắt ngực sau can thiệp gấp 1,8 lần so với chi phí điều trị cho bệnh nhân không có triệu chứng đau thắt ngực sau can thiệp với giá trị $p<0.001$ [9]. Đau ngực sẽ khiến người bệnh hoạt động thể chất giảm sút, chi phí điều trị tăng cao, nguy cơ tái hẹp trong stent, tinh thần người bệnh lo lắng,... Chính vì vậy làm cho CLCS của người bệnh giảm sút.

Kết quả (bảng 4 và 5), tình trạng suy tim phân độ theo NYHA có sự khác biệt giữa các nhóm ( $p<$ 0.05 ) tại các thời điểm trước và sau can thiệp. Điểm CLCS của nhóm không có triệu chứng suy tim sau can thiêp có điểm CLCS $(2.2 \pm 0.3$ đến $2.6 \pm 0.3)$, NYHA độ III có điểm CLCS thấp (1.7 \pm 0.6 đến $1.9 \pm 0.1)$. Như vậy, tình trạng suy tim phân đô theo NYHA có liên quan đến CLCS của người bệnh sau can thiêp ĐMV qua da.

Kết quả (bảng 4 và 5 ), điểm CLCS về tình trạng sức khỏe giữa các nhóm trước can thiệp không có sự khác biệt ( $p>0.05)$, có sự khác biệt giữa các nhóm sau can thiệp $(p<0.001)$. Tình trạng sức khỏe sau can thiệp 6 tháng có sự khác biệt so với trước can thiệp $(p<0.05)$. Khổng có sự khác biệt ở thời điểm 1 tháng và 3 tháng sau can thiệp với $p>0.05$. Điểm CLCS giữa các nhóm có tình trạng sức khỏe tệ, bình thường và tốt tại các thời điểm sau can thiệp 1 tháng, 3 tháng và 6 tháng có sự khác nhau $(p<0.05)$. Nhóm sức khỏe tê có điểm HeartQoL (1.2 \pm 0.3 đến 2.6$)$ thấp hơn các nhóm khác. Staniute nhận thấy tình trạng sức khỏe người bệnh cảm thấy mệt mỏi (tề, rất tệ) là yếu tố quan trọng, quyết định đến CLCS của bệnh nhân mắc bệnh lý ĐMV [10]. Nghiên cứu này của chúng tôi một lần nữa nói lên tình trạng sức khỏe của người bệnh là yếu tố quyết định quan trọng nhất đối với điểm HeartQoL hay nói cách khác sức khỏe ảnh hưởng lớn tới chất lượng cuộc sống của người bệnh.

\section{KẾT LUẬN}

Phần lớn bệnh nhân sau sáu tháng can thiệp ĐMV qua da có CLCS tốt theo thang điểm HeartQoL, giai đoạn này ít bị ảnh hưởng của quá trình can thiệp. Các yếu tố còn tồn tại của bệnh như đau ngực, suy tim khó thở theo NYHA, và các yếu tố không do bệnh như tình trạng sức khỏe, đặc điểm giới tính và trình độ học vấn có liên quan đến CLCS của người bệnh sau can thiệp.

\section{TÀI LIÊU THAM KHẢO}

1. Nguyễn Thị Kim Sáng (2019), Nghiên cứu Chất lương cuôc sống của bênh nhân sau can thiêp mạch vành trên bệnh nhân hội chứng vành cấp hoăc bệnh tim thiếu máu cục bộ dựa trên bộ câu hỏi SeatAngina. Tạp chí tim mạch học.

2. Darvishpour, A., et al.(2017), Factors associated with quality of life in patients undergoing coronary angioplasty. Int J Health Sci (Qassim). 11(4): p. 35-41.

3. Yinko, S.S.L.L., et al.(2014), Health\&\#x 2010; Related Quality of Life in Premature Acute Coronary Syndrome: Does Patient Sex or Gender Really Matter? 3(4): p. e000901.

4. Jankowska-Polańska, B., et al.(2016), Sex differences in the quality of life of patients with acute coronary syndrome treated with percutaneous coronary intervention after a 3-year follow-up. Patient Prefer Adherence, 10: p. 1279-87.

5. Li, $\mathbf{R}_{\text {, }}$ et al.(2012), Quality of life after percutaneous coronary intervention in the elderly with acute coronary syndrome. International Journal of Cardiology, 155(1): p. 90-96.

6. Shan, L., A. Saxena, and R. McMahon (2014), A systematic review on the quality of life benefits after percutaneous coronary intervention in the elderly. Cardiology, 129(1): p. 46-54.

7. Yazdani-Bakhsh, R., et al. (2016), Comparison of health-related quality of life after percutaneous coronary intervention and coronary artery bypass surgery. ARYA Atheroscler, 12(3): p. 124-131.

8. Holubkov, $\mathbf{R}_{\text {., }}$ et al.(2002) Angina 1 year after percutaneous coronary intervention: A report from the NHLBI Dynamic Registry. American Heart Journal, 144(5): p. 826-833.

9. Ben-Yehuda, O., et al.(2016), Angina and associated healthcare costs following percutaneous coronary intervention: a real-world analysis from a multi-payer database. 88(7): p. 1017-1024. 